\title{
Prevalence and Alternative Treatment of Head-Lice Infestation in Rural Thailand: A Community-Based Study
}

\author{
On-uma Singhasivanon 1,*, Saranath Lawpoolsri', Mathirut Mungthin², Surapon Yimsamran', \\ Ngamphol Soonthornworasiri', Srivicha Krudsood ${ }^{1}$ \\ ${ }^{1}$ Department of Tropical Hygiene, Faculty of Tropical Medicine, Mahidol University, Bangkok, Thailand; '2Department of Pharmacology, \\ Phramongkutklao College of Medicine, Bangkok, Thailand
}

\begin{abstract}
Head-lice infestation, pediculosis capitis, remains a public-health burden in many countries. The widely used first-line pediculicides and alternative treatments are often too costly for use in poor socio-economic settings. Ivermectin has been considered an alternate treatment for field practice. This study was composed of 2 parts, a cross-sectional survey and an intervention study. The main objectives were to determine the prevalence and potential factors associated with head-lice infestation, and to evaluate the effectiveness and safety of oral ivermectin administration. A community-based cross-sectional survey was conducted among 890 villagers in rural areas along Thai-Myanmar border. Females with infestations were eligible for the intervention study, and 181 participated in the intervention study. A post-treatment survey was conducted to assess acceptance of ivermectin as a treatment choice. Data analysis used descriptive statistics and a generalized-estimation-equation model adjusted for cluster effect. The study revealed the prevalence of head-lice infestation was $50 \%$ among females and only $3 \%$ among males. Age stratification showed a high prevalence among females aged $<20$ years, and among $50 \%$ of female school-children. The prevalence was persistent among those with a history of infestation. The major risk factors were residing in a setting with other infected cases, and sharing a hair comb. The study also confirmed that ivermectin was safe and effective for field-based practice. It was considered a preferable treatment option. In conclusion, behavior-change communication should be implemented to reduce the observed high prevalence of headlice infestation. Ivermectin may be an alternative choice for head-lice treatment, especially in remote areas.
\end{abstract}

Key words: Head louse, ivermectin, rural health, community-based study

\section{INTRODUCTION}

Infestation with Pediculus humanus capitis, commonly named head lice, has been a persistent problem worldwide. Each year, hundreds of millions of people suffer from head-lice infestation $[1,2]$. Although infestation does not cause a severe health problem, it is a personal and public health burden physically, psychologically, and socially. Infestation has been reported mainly among school children, people with poor hygiene habits, and people residing in resource-poor communities [38]. Reported prevalence varied, even among studies performed in the same country, due to several factors, including sample size and study sites with different sociocultural and socioeco-

- Received 19 July 2019, revised 4 September 2019, accepted 21 September 2019.

*Corresponding author (singha.onuma@gmail.com)

(c) 2019, Korean Society for Parasitology and Tropical Medicine

This is an Open Access article distributed under the terms of the Creative Commons Attribution Non-Commercial License (http://creativecommons.org/licenses/by-nc/4.0) which permits unrestricted non-commercial use, distribution, and reproduction in any

medium, provided the original work is properly cited. nomic status [9]. In Thailand, several studies in different areas during 1981-2017 reported prevalence rates ranging from $15.1 \%$ to $86.1 \%$ [10-16].

Various treatments are available for head-lice infestation. In Thailand, the gold standard treatment for head lice is topical $25 \%$ benzyl benzoate lotion, which requires at least 2 applications. Typically, the infested person will apply approximately $30 \mathrm{ml}$ of topical $25 \%$ benzyl benzoate lotion thoroughly onto a dry scalp until wet and leave the lotion on the affected area for 12 to $24 \mathrm{hr}$ before rinsing off with shampoo and water; application is usually repeated on Day 7. This treatment has been reported to cause irritation and burning sensations, especially in the scratched or infected scalp $[17,18]$. Several oral-ivermectin treatments have been studied, particularly in hard-to-treat head-lice infestations [17-23]. This treatment has not yet been tested in Thailand.

This study comprised 2 parts. The objectives of the first part were to determine the prevalence of head lice and to identify potential factors associated with head-lice infestation in rural Thai- 
land. The second part of the study aimed to evaluate the effectiveness of oral ivermectin administration among infested persons.

\section{MATERIALS AND METHODS}

\section{Study sites and study participants}

The study sites were 3 rural village communities along the Thai-Myanmar border (i.e., Tanaosri Subdistrict, Suan Phung District, Ratchaburi Province), with a total of about 3,000 permanent residents. Eligible study participants were those who resided permanently in the selected villages, age $\geq 5$ years, willing to provide their background information and test for head-lice infestation. For Part I, a community-based survey was conducted using a systematic sampling technique to select households, then requesting willingness of household members to participate in the study. Study participants positive for head-lice infestation were eligible for Part II of the study. The eligibility criteria for Part II also included age $\geq 5$ years, body weight $\geq 15 \mathrm{~kg}$, not being pregnant or lactating, not being treated with pediculicidal agents within the previous 14 days, not having uncontrolled systemic underlying disease, and having no history of allergy to the study drug.

\section{Determination of head-lice infestation}

The diagnosis of head-lice infestation in this study used the method of a previous study, where active infestation was defined as the presence of living head lice, determined with a finetoothed de-lousing comb to detect living head lice under natural sunlight [22]. The detection of viable nits (louse eggs) was also considered positive [24]. In the present study, the detection of a living head louse was considered an active infestation by using a fine-toothed de-lousing comb under natural sunlight, after combing the hair 20 times and visual observation above the ears and along the nape of the neck. Identification was reported as number of nymph, adult head lice, and nits.Each participant used their own comb, which was provided by the investigators to prevent head-to-head contamination. A positive case was defined as the detection of at least 1 living head louse.

\section{Intervention and outcome measures}

For Part II, a trained research team study administered oral ivermectin at a dosage of $200 \mu \mathrm{g} / \mathrm{kg}$ Day 0, repeated on Day 7, 1 $\mathrm{hr}$ before a meal. Cure was defined as the absence of living head lice post-treatment, on Days 7, 14, and 28. Safety was measured by participants' self-reporting of any adverse reactions during or after treatment. Beside self-reported adverse reactions, physical examinations were performed on Days $0,7,14$, and 28. Five milliliters of whole blood were obtained from each participant on Days 0 and 14 by well-trained certified nurses for laboratory testing of complete blood count (CBC), blood chemistry profiles (liver and kidney function), and electrolytes.

\section{Data collection}

For part I, the questionnaire was developed to collect potential risk factors of head-lice infestation, and comprised 2 main sections, personal characteristics, and hygiene behaviors. The research team interviewed the study participants, or the guardians of the children who were willing to participate in the study. The interview was conducted before measuring the hair length and determining infestation. At the end of Part II, a post-treatment survey was conducted to collect participants' perceptions of treatment. The post-treatment questionnaire assessed the satisfaction and acceptability of the users.

\section{Data analysis}

Descriptive statistics were used to determine the prevalence of infestation among different sub-groups of the study participants. A generalized estimation equation model of binary outcome among individuals clustered in the same residence (household) was used to estimate prevalence ratios among the study participants with potential risk factors. Cure rates were described at Days 7, 14, and 28. Complaints and side effects were presented descriptively. Due to non-responses and incomplete data, all analyses were performed based on complete information for each variable.

\section{Ethical considerations}

This study was approved by the Ethics Committee of the Faculty of Tropical Medicine. All participants were informed about the project objectives and the research procedures, and they were advised they could refuse to join or withdraw from the study at any time without negative consequences. Informed consent or assent were obtained from all participants, depending on age.

\section{RESULTS}

\section{Prevalence and risk factors for head-lice infestation}

In the community survey, 890 participants from 9 hamlets in 3 villages joined the study. All were willing to be tested for 
Table 1. Prevalence of head lice in rural community

\begin{tabular}{lcc}
\hline Characteristics & $\mathrm{n} / \mathrm{N}$ & Prevalence $(\%)$ \\
\hline Gender $(\mathrm{n}=890)$ & & \\
$\quad$ Male & $7 / 231$ & 3.0 \\
Female & $330 / 659$ & 50.1 \\
Age $(\mathrm{yr})(\mathrm{n}=884)$ & & \\
$<10$ & $117 / 326$ & 54.3 \\
$11-20$ & $119 / 244$ & 48.8 \\
$21-30$ & $13 / 84$ & 15.5 \\
$31-40$ & $17 / 90$ & 18.9 \\
$>40$ & $9 / 140$ & 6.4 \\
Schoolchildren $(\mathrm{n}=890)$ & & \\
Yes & $286 / 529$ & 54.1 \\
No & $51 / 361$ & 14.1 \\
\hline
\end{tabular}

head lice. As shown in Table 1, about half of the 659 women in the study area were infested with head lice, compared with only $3 \%$ of the 231 men. About half of the infested cases were aged 5-20 years; a decreasing trend was observed, with 15-20\% among those aged 21-40 years, and 6\% among those aged $>40$ years. About half of the infested cases were schoolchildren.

To avoid possible bias due to the small number of male cases, only the female study participants were included in the analysis of risk factors associated with head-lice infestation. As shown in Table 2, age was a significant risk factor associated with head-lice infestation, and prevalence decreased with ad-

Table 2. Potential risk factors of head-lice infestation among female participants

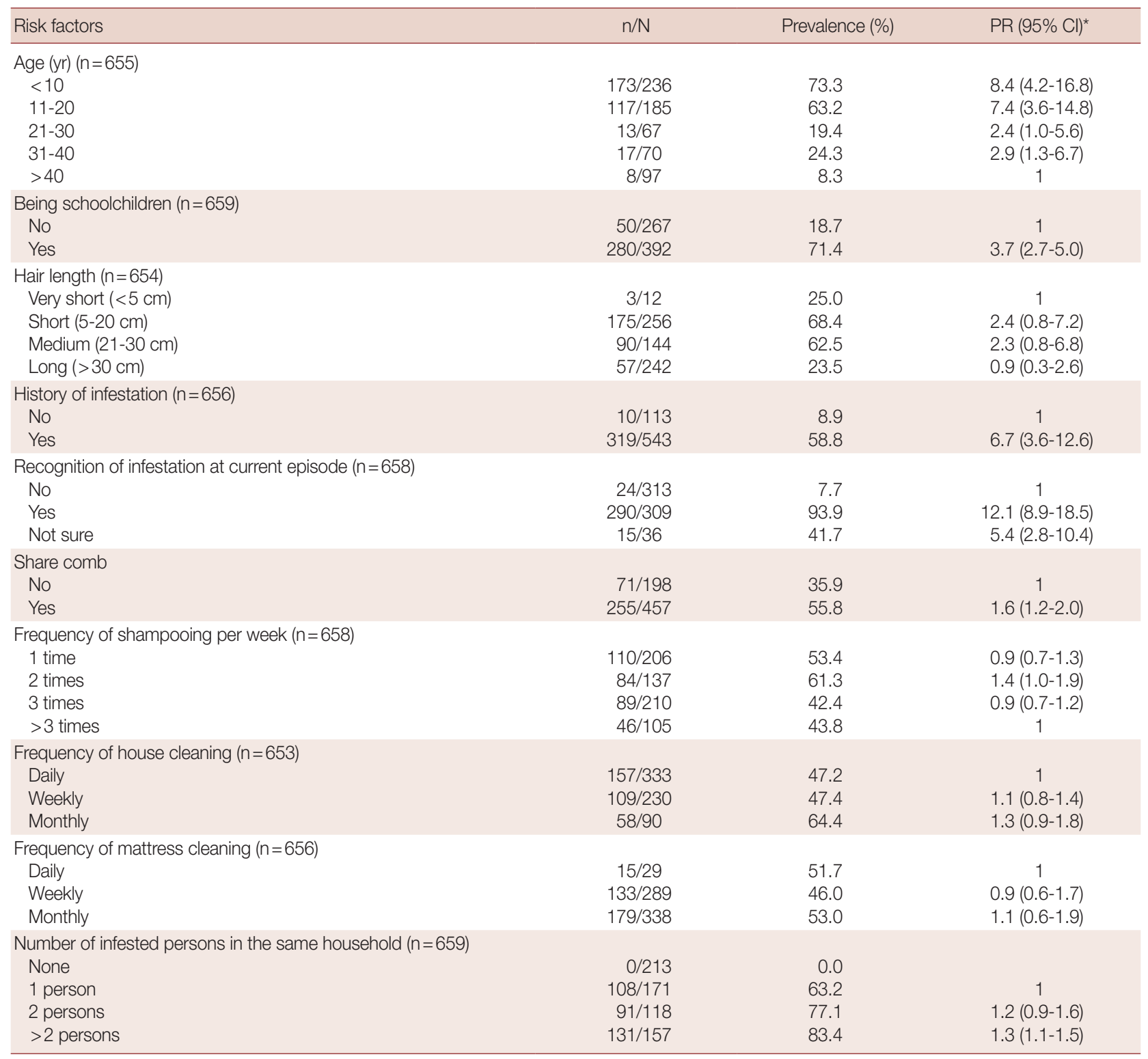

${ }^{*}$ Adjusted for cluster effect (residence). 
Table 3. Effectiveness and complaints/side effects of IVM administration $(n=181)$

\begin{tabular}{lcc}
\hline & $\mathrm{n}$ & Prevalence (\%) \\
\hline Effectiveness & & \\
$\quad$ Day 7 & 169 & 93.4 \\
Day 14 & 172 & 95.0 \\
Day 28 & 180 & 99.4 \\
Complaints/Side effects & & \\
$\quad$ Headache & 14 & 7.7 \\
Dizziness & 5 & 2.8 \\
Itch & 4 & 2.2 \\
Burning sensation & 0 & 0.0 \\
Vomiting & 1 & 0.6 \\
Stomach-ache & 1 & 0.6 \\
Nausea & 1 & 0.6 \\
\hline
\end{tabular}

vancing age. Prevalence among schoolchildren was 3.7-times (95\% CI: 2.7-5.0) higher than among those not of school age. Hair length appeared not to be associated with infestation. Those with a history of head-lice infestation had a 6.7-times (95\% CI: 3.6-12.6) higher prevalence of current infestation. Interestingly, about $7.7 \%$ of infested participants did not realize they were infested.

Regarding personal hygiene and risk behaviors, those who shared a comb in the family had a higher prevalence of infestation, at about 1.6 (95\% CI: 1.2-2.0), than those who did not. Frequency of shampooing, house cleaning, and mattress cleaning were shown not statistically significantly associated with infestation. A higher number of infested individuals in the same household appeared to be an increasing risk factor for infestation.

\section{Effectiveness of oral ivermectin (IVM)}

To evaluate the effectiveness of administering oral IVM to infested persons, 181 female cases agreed to participate. Cure rates were calculated at days 7, 14, and 28 (final follow-up). As shown in Table 3, cure rates increased from $93 \%$ at Day 7 to $99 \%$ at Day 28 . Among $7.7 \%$ of the study participants, headache was the main complaint after IVM application.

In the post-treatment survey, 128 study participants provided their opinions regarding the use of IVM as a treatment choice. As shown in Table 4, almost all participants indicated that IVM was easy to use and did not involve a long treatment time. Most participants also accepted that the treatment was safe. Interestingly, while about $87 \%$ preferred oral treatment compared with $13 \%$ preferring topical treatment, almost all would choose this medication as their treatment choice and use it to treat head-lice re-infestations in future.
Table 4. Satisfaction with and acceptance of IVM administration $(n=128)$

\begin{tabular}{|c|c|c|}
\hline \multirow{2}{*}{ Opinion } & Yes & No \\
\hline & \multicolumn{2}{|c|}{$\mathrm{n}(\%)$} \\
\hline Easy to use & $127(99.2)$ & $1(0.8)$ \\
\hline Acceptable time consumed in administration & $126(98.4)$ & $2(1.6)$ \\
\hline Safety & $125(97.7)$ & $3(2.3)$ \\
\hline Preference of oral treatment & $111(86.7)$ & $17(13.3)$ \\
\hline Preference as treatment choice & $127(99.2)$ & $1(0.8)$ \\
\hline Will use IVM in case of re-infestation & $125(97.7)$ & $3(2.3)$ \\
\hline
\end{tabular}

\section{DISCUSSION}

This community-based study was conducted to assess the head-lice infestation prevalence and risk factors among villagers in a rural area of Thailand. Unlike previous studies on head-lice infestation, this study employed cluster data analysis taking into consideration that infected and non-infected cases were clustered in similar residential areas or environments. This study also evaluated the effectiveness and acceptance of using a novel intervention, oral ivermectin, instead of the typical standard treatment for infested persons. If the new treatment were to be proved effective, it could be another choice for mass treatment administration in problematic areas.

The results of the study confirmed that head lice remain a bothersome and persistent problem even though many effective treatments were already in place. This study was conducted among villagers aged 5 to 76 years; the infection rate among females was about $50 \%$, and among males only $3 \%$; the oldest positive participant was 75 years of age. Like other studies worldwide $[3,9,12,13,15]$, age stratification showed a high prevalence among females aged $<20$ years, with about half among female schoolchildren.

This study revealed similar risk factors to other studies elsewhere $[15,16]$; many of the infested had a history of head-lice infestation. About 7.7\% did not recognize that they had head lice, and about $41 \%$ of those who were unsure were actually infected. This suggests that infested persons might not give their personal hygiene a high priority and could tolerate headlice infestation. Hair length was not statistically significantly associated with head-lice infestation. Personal hygiene, including frequency of shampooing per week, and a frequency of house and mattress cleaning, appeared not to be significant risk factors; these findings differed from a previous study [13]. Residing with other infected persons in the same setting was a 
potential risk factor. In attempt to reduce the burden in the community, mass treatment (MDA) might be one solution for handling the head-lice problem in high prevalence areas, particularly in school settings where transmission could proliferate dramatically. Most importantly, sharing a comb was shown to be a significant risk behavior for head-lice infestation. Those who shared a comb in the family had a higher prevalence of infestation than those who did not; the prevalence of infestation among those who shared a comb was $55.8 \%$, which was significantly higher than the prevalence of $35.9 \%$ among those who did not share a comb. The analysis was conducted using the generalized estimating equation (GEE) method to identify risk factors, with adjustment for study participants in the same cluster (household). Sharing a comb was one of the specific risks that could affect cure rate due to the infested person sharing household living conditions. The study results also indicated that higher numbers of infested individuals in the same household increased the risk of infestation. Behavioral-change communication was needed for the general public at the community level, not just in the school setting.

The first-line pediculicides in wide use were pyrethroids, $1 \%$ permethrin, $0.5 \%$ malathion, and 5\% benzyl alcohol [26]. Alternative treatment choices included dimethicone-based formulations, $0.5 \%$ topical ivermectin and spinosad [4,25-27]. However, these treatments are too expensive for use in poor socio-economic settings. Ivermectin was considered an alternative treatment in this study. Its efficacy has been supported by many studies $[7,17,18,22,28]$. The present study revealed that the cure rates of oral IVM were $93.4 \%, 95.0 \%$, and $99.4 \%$ on days 7,14 , and 28 , respectively. The study result revealed quite a high cure rate at Day 28. This observation may be influenced by the study design, since we had performed a community-based survey before implementing our intervention, the administration of oral ivermectin, among those positive for head-lice infestation and willing to participate in the study. However, for those not willing to participate, we had recommended treatment with the gold standard treatment, topical $25 \%$ benzyl benzoate lotion. With this approach, a high cure rate appeared to have accumulated and been sustained, as new infestations and/or re-infestations of people in the community could have been reduced over the follow-up period.

Regarding safety concerns, mild side effects were reported by a few IVM users, including headache, dizziness, itch stomachache, nausea or vomiting. While almost all users preferred IVM as their treatment choice, about 13\% indicated they still pre- ferred a topical form due to difficulties swallowing a tablet. Safety concerns were minimal, since the laboratory profiles of all study participants were in the normal range and no adverse results were observed. This study had some limitations. Topical 25\% benzyl benzoate lotion is known to be effective and has been used as the gold standard treatment in Thailand for quite a long time; the present study was solely designed to explore the effects of a potential alternative, oral ivermectin. Therefore, no comparative analysis with the ivermectin group was performed. Moreover, there was an alternative and convenient method to cure lice infestation, i.e., washing the hair every day for 7 days with warm water and soap. The effectiveness of this traditional method should also be investigated further and assessed.

In conclusion, head-lice infestation remains a problem in rural areas of Thailand. High prevalence was reported among younger females, especially schoolchildren. The prevalence was persistent among those with a history of infestation. Major risk factors were residing in a setting with other infected cases, and sharing a hair-comb. Behavior-change communication should be implemented by local health authorities to reduce community burden. The present study confirmed that 2 doses of oral ivermectin $(200 \mu \mathrm{g} / \mathrm{kg}$ once per week over 2 weeks) was safe and effective for field-based practice and may be an alternative for head-lice treatment, especially in remote areas.

\section{ACKNOWLEDGMENT}

The authors would like to thank the Faculty of Tropical Medicine, Mahidol University, for supporting the study.

\section{CONFLICT OF INTEREST}

The authors declare no conflict of interest related to this study.

\section{REFERENCES}

1. Sangaré AK, Doumbo OK, Raoult D. Management and treatment of human lice. Biomed Res Int 2016; 2016: 8962685.

2. Chosidow O. Scabies and pediculosis. Lancet 2000; 355: 819826.

3. Moosazadeh M, Afshari M, Keianian H, Nezammahalleh A, Enayati AA. Prevalence of head-lice infestation and its associated factors among primary school students in Iran: a systematic re- 
view and meta-analysis. Osong Public Health Res Perspect 2015; 6: 346-356.

4. Villegas SC, Breitzka RL. Head lice and the use of spinosad. Clin Ther 2012; 34: 14-23.

5. Cummings C, Finlay JC, MacDonald NE. Head-lice infestations: a clinical update. Paediatr Child Health 2004; 9: 647-657.

6. Rajan U. Treatment of head-lice infestation with benzyl benzoate and pyrethrum. Singapore Med J 1975; 16: 297-300.

7. Munirathinam A, Sunish IP, Rajendran R, Tyagi BK. Impact of ivermectin drug combinations on Pediculus humanus capitis infestation in primary schoolchildren of south Indian rural villages. Int J Dermatol 2009; 48: 1201-1205.

8. Droogan J. Treatment and prevention of head lice and scabies. Nurs Times 1999; 95: 44-45.

9. Falagas ME, Matthaiou DK, Rafailidis PI, Panos G, Pappas G. Worldwide prevalence of head lice. Emerg Infect Dis 2008; 14: 1493-1494.

10. Prakong C, Bhuwanart UT. Head-lice infestation in remote areas of Thailand. J Depart Med Sci 1981; 25: 101-106.

11. Thavara U, Phan-Urai P, Malainual A, Chansang C. Pediculosis among school children in rural areas of Thailand. J Depart Med Sci 1988; 30: 191-199.

12. Wannapinyosheep S, Polseela P, Akarachantachote N, Nithikathkul C. The prevalence of Pediculus humanus capitis among primary school students in Bang Phli district, Samutprakarn, Thailand. Songkla Med J 2004; 22: 1-6.

13. Thanyavanich N, Maneekan P, Yimsamran S, Maneeboonyang W, Puangsa-art S, Wuthisen P, Prommongkol S, Rukmanee P, Chavez IF, Rukmanee N, Chaimungkun W, Charusabha C. Epidemiology and risk factors of pediculosis capitis in 5 primary schools near the Thai-Myanmar border in Ratchaburi province, Thailand. J Trop Med Parasitol 2009; 32: 65-74.

14. Rassami W, Soonwera M. Epidemiology of pediculosis capitis among schoolchildren in the eastern area of Bangkok, Thailand. Asian Pac J Trop Biomed 2012; 2: 901-904.

15. Anusai N, Somprasong N, Hanjangsit K, Maleelai K. Epidemiology of pediculosis capitis in primary school students in Warinchumrab District, Ubon Ratchathani Province. 12th Mahasarakham University Research Conference; 2016 Aug 4-5; Mahasara- kham: Mahasarakham University; 2016. pp 553-563.

16. Ruankham W, Winyangkul P, Bunchub N. Prevalence and factors of head lice infestation among primary school students in Northern Thailand. Asian Pac J Trop Dis 2016; 6: 778-782.

17. Levitt J. Oral Ivermectin is more effective than topical malathion in difficult-to-treat head-lice infestation. Arch Dis Child Educ Pract Ed 2011; 96: 200.

18. Ahmad HM, Abdel-Azim ES, Abdel-Aziz RT. Assessment of topical versus oral ivermectin as a treatment for head lice. Dermatol Ther 2014; 27: 307-310.

19. Chosidow O, Giraudeau B, Cottrell J, Izri A, Hofmann R, Mann $\mathrm{SG}$, Burgess I. Oral ivermectin versus malathion lotion for difficult-to-treat head lice. N Engl J Med 2010; 362: 896-905.

20. Ameen M, Arenas R, Villanueva-Reyes J, Ruiz-Esmenjaud J, Millar D, Dominguez-Duenas F. Oral ivermectin for treatment of pediculosis capitis. Pediatr Infect Dis J 2010; 29: 991-993.

21. Leulmi H, Diatta G, Sokhna C, Rolain JM, Raoult D. Assessment of oral ivermectin versus shampoo in the treatment of pediculosis (head-lice infestation) in rural areas of Sine-Saloum, Senegal. Int J Antimicrob Agents 2016; 48: 627-632.

22. Nofal A. Oral ivermectin for head lice: a comparison with $0.5 \%$ topical malathion lotion. J Dtsch Dermatol Ges 2010; 8: 985988.

23. Popescu CM, Popescu R. Effectiveness of oral ivermectin and malathion lotion for difficult-to-treat head lice. Arch Dermatol 2011; 147: 98-100.

24. Soleimani-Ahmadi M, Jaberhashemi SA, Zare M, Sanei-Dehkordi A. Prevalence of head-lice infestation and pediculicidal effect of permethrine shampoo in primary school girls in a low-income area in southeast of Iran. BMC Dermatol 2017; 17: 10.

25. Clark J, Yoon K, Pittendrigh B. Human lice: past, present and future control. Pestic Biochem Physiol 2013; 106: 162-171.

26. Bragg BN, Simon LV. Pediculosis humanis (Lice, Capitis, Pubis). StatPearls [Internet]. 2019. Available from: https://www.statpearls.com/kb/viewarticle/24248/.

27. Gunning K, Pippitt K, Kiraly B, Sayler M. Pediculosis and scabies: treatment update. Am Fam Physician 2012; 86: 535-541.

28. Chosidow A, Gendrel D. Safety of oral ivermectin in children. Arch Pediatr 2016; 23: 204-209 (in French). 